\title{
El scriptorium y la biblioteca del Monasterio de Piedra: noticias y evidencias materiales
}

\author{
Herbert GONZÁLEZ ZYMLA \\ (Departamento de Historia del Arte I, UCM) \\ (Centro Superior de Diseño de Moda de Madrid, UPM)
}

\section{Resumen}

El estudio del fondo bibliográfico de manuscritos que hubo en la biblioteca del Monasterio de Piedra es un asunto complejo. Tradicionalmente se ha afirmado que todo se perdió en la desamortización, pero esta afirmación es un tópico. Sería más exacto afirmar que hoy están en paradero desconocido o no es posible su identificación, reconociendo que una buena parte del fondo se perdió irremediablemente. El presente artículo ha permitido identificar, en el arco cronológico que va de 1195 a 1531, con seguridad total, nueve libros, de los cuales, ocho eran manuscritos y uno era impreso. Pese a que es un espectro de información limitado, se abre con él un nuevo campo de análisis y se pone en conocimiento de la comunidad científica la existencia de un centro productor y consumidor de libros durante la Baja Edad Media.

Palabras clave: Monasterio de Piedra; Biblioteca monástica; Monje Chantre; Libro de Apeos del Monasterio de Piedra; Regla de San Benito.

\section{The scriptorium and library of Monastery of Piedra: news and material evidence.}

\section{Abstract}

The study of the collection of books held in the library of the Monastery of Piedra is a complex issue. The loss of the whole collection during the Ecclesiastical Confiscations in the nineteenth century has been traditionally 
claimed, but this statement is theorethical. It would be more accurate to state that some of the units have not been identified yet and might stay in private hands whilst much of the collection is irreversibly lost. This article presents a total of nine books dated between 1195 and 1531, eight of them being manuscripts and one printed book. Although this is just a small sample of what the whole collection of books would have been, the limited information obtained out of them, opens a new field of analysis and values the role played by a centre which produced and purchased books during the late Middle Ages.

Keywords: Monastery of Piedra; Monastic Library; Chantre Monk; Apeos Book of the Monastery of Piedra; Rule of Saint Benedict.

El Real Monasterio Cisterciense de Santa María de Piedra fue fundado por iniciativa de Alfonso II de Aragón en 1195. ${ }^{1}$ La primera dotación de libros que hubo en Piedra fue la que llevaban consigo el abad Gaufredo de Rocaberti y sus compañeros que salieron de Poblet en 1194 para fundar el Monasterio de Piedra en los despoblados montañosos situados entre Calatayud y Daroca. Con seguridad, en el periodo en que se hicieron los preparativos fundacionales, entre 1186 y 1194, se hicieron las copias de los libros necesarios para la nueva fundación. El taller escriturario que asumió la fabricación de esas copias hubo de ser el scriptorium de Poblet. Entre los libros imprescindibles estaban: la Regla de San Benito; los libros para la liturgia de la misa: el Misal, los Santos cuatro Evangelios, el Gradual, el Leccionario y el Manual de oraciones; los libros para la liturgia de las horas: el Himnario, el Salterio y el Antifonario; una Biblia, en la versión elaborada por San Esteban Harding; y quizá algún manuscrito doctrinal propio de la orden como los Sermones y Epistolas de San Bernardo y el Exordium Cistercienses Coenobi. Los manuscritos fundacionales eran un tesoro espiritual. Aunque en el caso concreto de Piedra no ha llegado ninguno a nuestros días y, por tanto, no podemos distinguir cuáles fueron dotación de Poblet y cuáles pudieron serlo de Fontfroide y Claraval, cuando se compuso el Lumen Domus Petrae, entre 1670-1680, aún se tenía identificado:

El Misal se trujo del Monasterio de Poblet, al tiempo de su fundación, en donde están escritas las misas de tiempo y el sanctoral, conforme al estilo de los misales antiguos de la orden; del qual han usado los Señores Abades de este Monasterio para cantar las misas teniéndolo en frente de la

\footnotetext{
1 Archivo Histórico Nacional (AHN): Clero, Poblet, Carp. 2042, doc. 9. ArChivo de la Real ACADEmia de la Historia (ARAH): Colección de Manuscritos de Joaquín Traggia. Ms.B-138, f.159. Herbert GONZÁLEZ ZYMLA, «Sobre los posibles orígenes del Real Monasterio de Santa María de Piedra: precisiones acerca de su primera ubicación y sentido de su advocación mariana», Anales de Historia del Arte de la Universidad Complutense de Madrid, 13 (2003), pp. 27-82.
}

Titivillus, ISSN 2387-0915, ISSN-e 2603-9966, 1 (2015), pp. 13-26 
silla abacial en todos tiempos, entre tanto que se cantaba la misa conventual. En el qual libro (cuyas hojas son de pergamino) en la hoja que media entre las misas de tempore y las del santoral, que viene a estar en la mitad del cuerpo. ${ }^{2}$

Los abades de Poblet, Claraval y Císter gozaron, a lo largo de la Edad Media, del derecho de visita sobre Piedra. Al hacer la inspección, podían detectar carencias en las bibliotecas y mandar cubrirlas por medio de la censura pastoral. La censura no es asunto baladí, puesto que no está exenta de intereses económicos, dado que para no ser objeto de una segunda inspección, los manuscritos debían ser encargados a la casa mater y ello generó un circuito económico cerrado entre Poblet y Piedra basado en la disciplina. A través de la documentación conservada en el Archivo Histórico Nacional conocemos algunas de las visitas pastorales hechas por los abades de Poblet, Morimond y Claraval a Piedra. ${ }^{3}$ El carácter internacional de la orden y la celebración cada 4 años del Capítulo General, al que Piedra debía enviar un representante, podría explicar la llegada a Piedra de manuscritos procedentes de scriptoria franceses, como Císter, Claraval y el colegio de San Bernardo de la Universidad de París, a donde Piedra tenía derecho a enviar un alumno periódicamente. La historiografía tradicional ha minusvalorado la importancia de Piedra en el conjunto de monasterios hispanos, pero baste recordar que, a finales del siglo XIII, era el tercer monasterio ibérico que más contribuía al Capítulo General, sólo por detrás de Poblet y Osera. ${ }^{4}$

San Bernardo decía: Más se aprende en los bosques que en los libros. Los árboles y las rocas te enseñarán cosas que no aprenderás en otros lugares. ${ }^{5}$ Esta sentencia tiene un especial significado para el estudio de Piedra, dada la ubicación de la abadía en un singular paisaje con exuberante vegetación y cascadas. Teniendo en cuenta esta máxima, cabría esperar de los cistercienses de Piedra un cierto desinterés por las artes del libro, sin embargo la realidad fue bien distinta. Para cumplir

\footnotetext{
2 AHN: Lumen Domus Petrae. Cod. 55-B, pp. 1408-9. Herbert GONZÁLEZ ZYMLA, El Monasterio de Piedra. Fuentes y Donumentos, Madrid, 2014, p. 324.

${ }^{3}$ El abad de Poblet debía viajar 2 veces al año a Piedra para inspeccionar las cuentas y hacer las censuras pertinentes. Consta la inspección del abad de Poblet en las cuentas IV, VI, XII, XXVII, XXX, XLVI, LVII y LX del Libro de Bolsería. Archivo del Museo de Teruel (A. M. T): Libro de Bolsería del Monasterio de Piedra. f. 13. Concepción de la Fuente Cobos, Libro de apeos del Monasterio de Piedra 1334. Libro de cuenta de la Bolsería del Monasterio de Piedra 1307-48. Huesca, 2001, pp. 10 y 101. Guidon, abad de Morimond, visitó Piedra en 1429 y, en 1532, el abad de Claraval. AHN: Lumen Domus Petrae, Cod. 55 , p. 84 y $166-8$.

${ }^{4}$ Javier PÉreZ EMBID, El Cister en Castilla y León. Monacato y dominios rurales s. XII-XV, Salamanca, 1986, pp. 43-5.

5 Bernardo de Claraval, Obras Completas de San Bernardo de Claraval, Madrid, 1990, Epístola 101 y 106.
} 
correctamente la Regla de San Benito no bastaba con la dotación de libros enviada desde Poblet. De los libros matrices llegados en 1195 se tuvieron que hacer copias para disponer de varios ejemplares de la Regla, el Salterio y los Evangelios. La Regla de San Benito regula con sumo cuidado los días y tiempos litúrgicos en que el monje debe leer y la actitud de recogimiento interior y reverencia que debía tener cuando hacía las lecturas. ${ }^{6}$ Su último capítulo recomienda leer a diario y dedicar casi todo el domingo a hacer la Lectio Divina, consistente en memorizar y recitar el contenido de los libros que componen la Biblia, sin excluir los libros que derivan de ella o conducen a ella. Durante la cuaresma, el monje debía leer desde el amanecer hasta la hora tercera (9 de la mañana). Cada fraile debía recibir un volumen y leerlo completo. En verano los monjes trabajaban más, mientras que, en el invierno, leian más. ${ }^{7}$ Por tanto, no bastaba con un solo ejemplar de cada libro sino que, para cumplir correctamente la regla, debían existir varias copias hechas a partir de las matrices. Es así como nació en Piedra un taller escriturario que, en los siglos XIII y XIV, tenía como objetivo único abastecer al monasterio, las granjas de hermanos legos y las parroquias que dependían de la abadía. Los frailes copistas hacían estos trabajos obedeciendo al abad y, razonablemente, la cultura libraría de Piedra debía depender de los modelos formales marcados por los manuscritos de Poblet. Con el paso del tiempo también ejercieron cierta influencia otros centros de producción como Tarazona, Huerta, Veruela, Santa Fe, Rueda y Calatayud.

Aunque no sabemos desde cuándo existió un scriptorium en Piedra, el Libro de Bolsería, que contiene la contabilidad oficial del monasterio entre 1307 y 1348, demuestra la compra de papel y tintas. Las cantidades gastadas son tan significativas que sólo se entienden si se usan para fabricar libros. La cuenta 2 , del 11 de julio de 1308, registra el gasto de 8 dineros en papel; la cuenta 5, del 10 de enero de 1310, recoge el gasto de 12 dineros en paper e tinta; la cuenta 6, del 20 de noviembre de 1310, señala el gasto de 10 dineros en papel. La tinta de escribir no debe confundirse con la tinta de teñir. La cuenta 2 cifra el gasto de 21 sueldos y 6 dineros en comprar tres alqueces de tinta; ${ }^{8}$ si cada alquez son 12 cántaras y cada cántara 16,3 litros, se compraron 195,6 litros de tinta, una cantidad que debe interpretarse como tinte para hábitos. No se registra la compra de pergamino porque los cistercienses tuvieron una notable cabaña ganadera y lo fabricaban los hermanos legos conversos en las granjas de

\footnotetext{
${ }^{6}$ Benito de Nursia, Regla de San Benito de Nursia, Zamora, 1994, Cap. XLVIII, 22-3, p. 95 , LVIII, 9-20, pp. 108-9.

7 Wolfgang, BRAUnFELS, La arquitectura monacal en occidente, Barcelona, 1975, p. 41. Louis J., LEKAI, Los cistercienses. Ideales y realidad, Barcelona, 1987.

8 AMT: Libro de Bolsería de Piedra, fol. 3, 4v, 12 v, 16v. Fuente CoBos, Libro de apeos del Monasterio de Piedra 1334. Libro de cuenta de la Bolsería del Monasterio de Piedra 1307-1348, p. 83, 86,100 y 107.
}

Titivillus, ISSN 2387-0915, ISSN-e 2603-9966, 1 (2015), pp. 13-26 
Bellestar, Zaragocilla, Llumes, Ortix, Villar del Salz y Fuen del Buey.9 El Capítulo General mandaba que los manuscritos evitaran las abreviaturas y usaran letras pausadas, limpias y bien dibujadas con tinta oscura sobre pergamino. Los Institutia prohibieron los libros lujosos e impusieron evitar las miniaturas para que los monjes no se distrajesen. Sólo se permitía el ornato en las mayúsculas capitales de inicio de párrafo. ${ }^{10} \mathrm{El}$ scriptorium de Piedra se ajustó perfectamente a estas normas de severidad y sencillez. A día de hoy es difícil averiguar la identidad de los monjes que fabricaron los códices del scriptorium de Piedra. Como estaban sujetos a la obediencia al abad y cualquiera de ellos estaba capacitado para escribir, la producción de libros se mueve dentro del habitual anonimato cisterciense. Hubo tres cargos monásticos que podrían identificar a los escritores más activos: chantre, monje notario y cillerero.

El monje chantre, entre otras responsabilidades, debía velar por la integridad y buena conservación de libros y documentos, custodiaba la llave del armarium y era el responsable del scriptoria. ${ }^{11}$ Conocemos la identidad de algunos de los chantres de Piedra: en 1220, cuando la abadía recibió la granja de Zaragocilla, se cita al padre Domingo como cantoris, ${ }^{12}$ en la concordia de cesión de las salinas de Monterde, Abanto y Pardos, fechada en Huesca a 6 de las calendas de junio de 1268, firma frater Paschasius cantor, ${ }^{13}$ cuando Jaime II donó las salinas de Monterde a Piedra, a 6 de los idus de marzo de 1304, firma como chantre frater Vincentius. ${ }^{14}$ La cuenta 3 del Libro de Bolsería, de 3 de febrero de 1309, recoge como maestro cantor a fray Mateo y la cuenta 5, de 10 de enero de 1310, registra al cantor X sueldos para adobar los libros. ${ }^{15} \mathrm{Si}$ el chantre es el responsable del scriptorium el monje notario era uno de los que trabajaban

\footnotetext{
${ }^{9}$ Herbert, GonZÁLEZ ZYMLA, "La granja de Bellestar y su relación con el Monasterio de Piedra", Revista de Arqueología. Madrid, 354, ( 2010), pp. 24-35. Herbert, GonZÁleZ ZYMLA, "La granja de Zaragocilla y su relación con el Monasterio de Piedra", Anales de Historia del Arte. Madrid (2010), p. 111-121. Herbert, GonZÁlez ZyMLA, "La iglesia parroquial de Llumes y el Real Monasterio Cisterciense de Santa María de Piedra". Anales de Historia del Arte. Madrid (2010), p. 249-265.

10 Turk, J. Cistercii Statuta Antiquissima. XIII. Analecta 4, 1948, p.1-159.

11 Jean François, Leroux-DHuYs, 1999, p. 60-61. El chantre de Piedra custodiaba los documentos del monasterio y los de las familias más poderosas, como los Azagra de Albarracín y los Señores de Molina, que depositaban documentos en Piedra por ser lugar seguro. AHN: Lumen Domus Petrae. Cod. 55, pp. 188 y 304.

12 AHN: Lumen Domus Petrae. Cod. 55, p. 578. Herbert, GonZÁLEZ ZyMLA, 2010, p. 111 121.

13 AHN: Clero, Piedra, carp. 3676, doc. 7 y 8. Lumen Domus Petrae. Cod. 55-B, p. 1530. ArChivo de la Corona de Aragón (ACA): Chancillería, Pergaminos, Serie general, doc. 1945.

14 AHN: Lumen Domus Petrae. Cod. 55-B, p. 1534.

15 AMT: Libro de Bolsería de Piedra, fol. 11r. Fuente CoBos, Libro de apeos del Monasterio de Piedra..., p. 98.
} 
en él. Jaime I concedió a 8 de los idus de mayo de 1251 que el abad Arnaldo y los monjes de Piedra:

Siempre y quando algún caballero o cavalleros o qualquiera otra persona secular, enfermase en el dicho Monasterio y quisiese hacer testamento y disponer sus bienes; que en este caso, qualquier monge del mismo Monasterio pudiese recibir y testificar el dicho testamento y los actos conferentes a disposición testamentaria; los quales quiere su Magestad y determina que hagan la misma fe que si estubiesen testificados por escribano público. ${ }^{16}$

A 16 de las calendas de noviembre de 1262, Fray Domingo de los pobres, redactó como monje notario una concordia con los habitantes de Carenas para rebajar las cargas fiscales que pagaban a la abadía. En el testamento de Pedro González, hijo del Conde de Molina Gonzalo Pérez, figura Fray Silvestre como monje notario de sus últimas voluntades a 5 de los idus de octubre de 1268, incluyendo la donación de 1000 maravedíes para la fábrica de Piedra. ${ }^{17}$

Los códices más antiguos compuestos en Piedra son el Libro de Bolsería y el Libro de Apeos. Ambos son obra del siglo XIV, los adquirió en el mercado de Calatayud, en los años posteriores a la desamortización, Vicente de la Fuente Bueno, académico de número, medalla 34, de la Real Academia de la Historia. ${ }^{18}$ Actualmente se conservan en el Museo de Teruel, por donación de José Luis Sotoca y en 2001 fueron transcritos por Concepción Fuente Cobos. El Libro de Bolsería contiene las 65 cuentas monásticas oficiales que se hicieron entre 1307 y 1348, la primera y la última incompletas. El códice tiene 77 folios escritos sobre pergamino en letra fracturada de color negro. Mide 29 x $20 \mathrm{~cm}$. y es posible que su extensión fuera mayor. Es un libro administrativo y todas las cuentas, salvo alguna pequeña excepción, tienen el mismo esquema. Es obra de varios maestros escriturarios cuyos nombres no se recogen. Hay que pensar que era una de las responsabilidades del cillerero mayor y que las diferentes letras se corresponden con los nombres que figuran ejerciendo ese cargo. En algunos casos esto es seguro y en otros probable porque en Piedra hubo cillerero mayor, cillerero medio, cillerero menor y bolsero. A veces coincide que cillerero y bolsero son la misma persona, en tales casos también debe adjudicársele el tipo de letra de la cuenta. El 3 de enero de 1314 consta como cillerero Fray Vicente Mascarón, autor de las cuentas 16 y 17. Fray Juan de Caxar fue autor de las cuentas 31 y 32. En 1316 Fray Pedro Alcalde era el cillerero y en 1330 el cillerero mayor era Fray Pascual de Berlanga. Hasta 1335 hubo en Piedra un único bolsero. La cuenta 40, fechada el 4 de abril de 1335,

16 AHN. Lumen Domus Petrae, Cod. 55, pp. 203-4.

17 AHN. Lumen Domus Petrae, Cod. 55, pp. 270-2 y 791-2

18 Anuario de la Real Academia de la Historia, Madrid, 2014, p. 253.

Titivillus, ISSN 2387-0915, ISSN-e 2603-9966, 1 (2015), pp. 13-26 
describe cómo el cillerero Fray Lorenzo malversó caudales y probadas las acusaciones, el XXIV abad de Piedra, Juan de Segarra y de Ibdes, expulsó a fray Lorenzo. Para que no volviera a suceder un episodio igual, se arbitró que hubiera dos bolseros controlándose el uno al otro. A partir de esa fecha no hay seguridad acerca del monje que escribe la cuenta y en consecuencia no se pueden identificar los rasgos escriturarios con la identidad del religioso. En 1336 son bolseros Fray Pascual de Molina y Fray Bernardo. Desde enero de 1332 figura como cillerero Fray Domingo Lechón que, además, fue procurador del monasterio, responsable en 1330 de la granja de Bellestar y en 1343 de las salinas de Abanto. Las cuentas 46 y 47, fechadas el 27 de marzo de 1338 y el 20 de junio de 1338, certifican un momento muy delicado en las finanzas de Piedra, puesto que en la ceca sólo había 5 sueldos y una deuda de 1800. El bolsero, Fray Pascual de Jaca, fue destituido y se nombró a Fray Juan de Caxar y a Fray Pascual de Molina, que pidieron un crédito de 1000 sueldos a un judío bilbilitano llamado Caçon, a quien se devolvió, el 23 de junio de 1339, la cantidad de 1300 sueldos, lo que supone un interés de casi $30 \%$. En un documento de 1340 figura como monje bolsero Fray Pascual de la Oliva, que alcanzó, andados los años, el cargo de XXVIII abad entre 1348 y 1361. Ese mismo año de 1340, el 31 de marzo, está citado como celario mayor Fray Domingo Monzón. ${ }^{19}$. El Libro de bolsería es un códice de uso práctico que permite estudiar la vida económica de Piedra y relacionar los tipos de letra con los monjes que ejercían el cargo de cillerero bolsero en el arco cronológico de 1307 a 1348. A la larga, los rasgos singulares de estas formas de escribir deberían permitir la identificación de códices posiblemente fabricados en Piedra.

El Libro de Apeos de Piedra es un registro universal de las propiedades que los cistercienses tenían en 1344, lo que data con seguridad el códice. Mide 29 x $20 \mathrm{~cm}$. Se compuso sobre pergamino, tiene 31 folios y 32 líneas por folio, en letra fracturada de tinta negra de muy fácil lectura, se halla incompleto e ignoramos cuál fue su verdadero tamaño. Los registros se ordenan según los pueblos donde se encontraban las fincas rústicas y urbanas, se indican los límites geográficos y, en la mayor parte de los casos, las pensiones y censales, así como la identidad de quiénes los pagaban. Su estudio es muy útil para evaluar la red de relaciones socio-económicas que sustentaban la abadía. Se le cita como Cabreo Antiguo de Piedra, para distinguirlo de los Cabreos modernos, compuestos en las décadas de 1670-1680 y titulados Lumen Domus Petrae. ${ }^{20}$

\footnotetext{
19 AMT: Libro de Bolsería de Piedra. Cuenta 16, 17, 41, 47, fol. 52, 57 y 58, 195-226. Cuenta 48, fol. 58 y 59. AHN: Lumen Domus Petrae. Cod. 55, p. 8, 703-4. Clero, Piedra, carp. 3692, doc. 17carp. 3693, doc. 12, carp. 3696, doc. 18. FUENTE COBOS, Libro de apeos del Monasterio de Piedra...

${ }^{20}$ AHN: Lumen Domus Petrae. Cod. 55, p. 1492, 1573 y 1593 y Cod. 56.
} 
En 2002 la casa Durán subastó, procedente de una colección particular, una Regla de San Benito de Nursia que, a juzgar por el tipo de letra libraria aragonesa, de formato fracturado y lectura clara debe ser cisterciense de mediados del XV. La ficha de catalogación afirmaba que procedía del scriptorium de Piedra sin hacer más indicaciones. Es posible que esa información la transmitiera el propietario del manuscrito ya que en la misma subasta se vendieron otros libros procedentes de una biblioteca aragonesa. Está encuadernada en piel, algo deteriorada, sobre tabla, con cierres metálicos originales; ha perdido los 6 primeros fol. y conserva desde el fol. VIII al CVIII. Al final hay 3 fol. sueltos casi ilegibles. Tiene 15 líneas por fol. y 3 tamaños de letra: letra capitular morada y roja, mayúscula, realzada en color amarillo y letra de menor tamaño para el cuerpo de texto. Esta letra es obra de un copista cuyos rasgos escriturarios son diferentes a los de un segundo escritor que es quien hizo los comentarios marginales relativos al modo en que debía cumplirse la regla, algunos muy profusos. No es posible saber si tales comentarios se escribieron al tiempo que se componía el códice o si fueron añadidos después. Ninguno de los maestros escriturarios está identificado, ni hay firma, pero las dos manos son claras. El catálogo puso el manuscrito en relación con Fray Martín de Vargas, reformador de la observancia cisterciense en Castilla, monje profeso de Piedra y fundador en 1425 de Monte Sión en Toledo. Como Monte Sión fue fundación de Piedra, cabe preguntarse si el códice no sería uno de los que componían el equipaje fundacional dado por la casa mater a su filial y, por tanto, habría sido fabricado en Piedra en la década de 1420, copiando la Regla de San Benito que el abad Masanet dio en 1194 al abad Gaufredo. Es tentador pensar que este códice sería como el que se usaba en Piedra cuando un donado o un nuevo fraile profesaban. La ceremonia de aceptación incluía el juramento del neófito tocando corporalmente la Regla de San Benito o los Santos Evangelios, ritualidad muy bien descrita en la carta de profesión de un donado llamado Pedro de Piedrafita, hecha el 12 de enero de 1437 ante el notario de Nuévalos, Juan Martínez de Arandiga. ${ }^{21}$

Tenemos noticia de un Ritual Antiguo manuscrito de este monasterio, que es un libro en quarto aforrado con tablas cubiertas de becerro negro, que contenía en el fol. 10 la fórmula de absolución de pecados ajustada a los indultos apostólicos dados por Eugenio IV, que fue Papa entre 1431 y 1447, y su sucesor, Nicolás V, Pontífice entre 1447 y 1455. En consecuencia, aunque no se ha identificado el manuscrito, su composición tendría que ser posterior a esa data. ${ }^{22}$

\footnotetext{
${ }^{21}$ Catálogo de la Subasta extraordinaria del jueves 20 de mayo del año 2002. 2002, p. 88 y 89, $\mathrm{n}^{\circ}$ 3252 y 3253. Damián, YÁnEZ NEIRA, En el Monasterio de Piedra se forjó la congregación de Castilla, Zaragoza, 1975. AHN: Lumen Domus Petrae, Cod. 55-B, p. 1090-1.

22 AHN: Clero, Piedra, carp. 3725, doc. 14. Lumen Domus Petrae, Cod. 55-B, p. 22 y 56.
}

Titivillus, ISSN 2387-0915, ISSN-e 2603-9966, 1 (2015), pp. 13-26 
A finales del siglo XV e inicios del XVI Piedra conoció un momento de esplendor coincidente con el gobierno del XXXV abad, Pedro Serrano, que lo fue entre 1461 y 1488, y del XXXVI abad, García del Portillo, que gobernó Piedra entre 1488 y 1531. Ambos prelados fueron consejeros de Fernando el Católico y se les cita como maestros en sacra teología, lo que supone que tenían el grado de doctor. En 1522 profesó en Piedra un nieto de Fernando el Católico, Fray Hernando de Aragón, hijo de Ana Gurrea y del arzobispo de Zaragoza, Alonso de Aragón. Fray Hernando fue abad de Veruela, arzobispo de Zaragoza y virrey de Aragón. A este periodo esplendente corresponde la composición en Piedra de 2 códices que contenían las visitas pastorales del abad Serrano y el abad Portillo. Juan IX, abad de Cister, con autoridad del Capítulo General y de los Reyes Católicos comisionó, según documentos dados en Dijon a 4 de diciembre de 1479 y en Toledo, el 22 de abril de 1480, al abad Serrano para que visitase y reformase los monasterios cistercienses de Aragón y Castilla. Al tiempo que hacía las visitas se compuso un libro Varios asuntos relativos a la Orden del Císter, y en particular a la visita que hizo a los monasterios de la misma el abad Don Pedro Serrano, hoy en el Archivo Histórico Nacional. El cargo de visitador general lo mantuvo el abad Portillo según nombramientos de 1489 para Aragón, Castilla y Portugal, renovado en 1491 y ampliado a Navarra en 1511. Según el Lumen Domus Petrae existía un Libro de visitas que contenía el modelo para hacer los interrogatorios y las visitas propiamente dichas que se hicieron entre 1515 y 1531 a las Huelgas Reales, Hospital del Rey, Fuen Caliente, Tulenbras, Trasobares, Casbas, Santa Fe, Veruela, Iranzu, Leire, Oliva y Fitero. También contenía la correspondencia entre el abad Portillo y Jacobo, General de Cister. El manuscrito está en paradero desconocido y sería bueno localizarlo para compararlo con el anterior. ${ }^{23}$

En Piedra también se adquirían libros ya fabricados y los pagaban, no sin dificultad, a medida que tenían recursos económicos. Así se demuestra al examinar la cuenta 5 del libro de Bolsería, de 10 de enero de 1310, que registra el gasto de 9 sueldos para el salterio de Carenas, ${ }^{24}$ y ponerla en relación con la cuenta 6, de 20 de noviembre de 1310, que registra un segundo pago: Espensa pro conputatione. In primis, al salterio de Carenas XII dineros. ${ }^{25} \mathrm{La}$ compra de este libro, que no ha llegado a nuestros días, no tenía por objeto enriquecer la biblioteca monástica, sino dotar de libros a la parroquia de Carenas. No se dice quién lo fabricó ni dónde se adquirieron, tan sólo se registra el gasto y el destino del códice. Lo relevante del cómputo es que constata la existencia de

\footnotetext{
${ }^{23}$ AHN: Clero, Piedra, carp. 3744, doc. 12. Lumen Domus Petrae. Cod. 55, p. 100-2.

${ }^{24}$ AMT: Libro de Bolsería de Piedra, fol. 14 v. Concepción de la, FUENTE COBOs, Libro de apeos del Monasterio de Piedra..., p. 104.

${ }^{25}$ Fuente CoBos, Libro de apeos del Monasterio de Piedra..., fol. 16v, p. 107.
} 
una política de adquisiciones a comienzos del siglo XIV y un cierto mercado de libros en el valle del Jalón. ${ }^{26}$

Desde 1245 Piedra podía enviar estudiantes a formarse al colegio de San Bernardo de París. A lo largo de los siglos XIII y XIV surgieron otros centros de enseñanza en Montpellier, Toulouse, Estella, Salamanca y Lérida. A partir de 1419, fecha en que Benedicto XIII fundó una cátedra de Teología en Santa María de Calatayud, el Estudio General Bilbilitano, los monjes de Piedra tuvieron un centro docente cercano al que anualmente enviaban 3 monjes que residían en la casa hospicio que el monasterio tenía en la Calle Gotor de Calatayud. ${ }^{27}$ Fue entonces cuando debió nacer un circuito económico de producción de manuscritos en Calatayud pensado para satisfacer las necesidades de los profesores y estudiantes de este centro docente. A finales del siglo XV se han podido documentar 2 artesanos del libro que, sin ser monjes, vivieron al amparo de Piedra y hubieron de estar al servicio del monasterio: un maestro escritor de libros de iglesia, llamado Pascual Julián, y un iluminador, llamado Pascual Pérez, ambos vivían en Carenas según el fogaje de 1495, ${ }^{28}$ como este pueblo era parte del dominio señorial de Piedra, es seguro que ambos profesionales del libro fueron tributarios del monasterio y no es difícil imaginarlos con su actividad orientada a asumir encargos del monasterio y del estudio de Calatayud y otras iglesias. Algunos buenos ejemplos de manuscritos de fabricación bilbilitana se conservan en la colegiata de Santa María de Calatayud como el libro Chantre de 1382, el Breviario bilbilitano del siglo XIV donado en 1463 por el Cardenal y obispo de Tarazona Jorge Bardaxi y el Misal gótico del siglo XIV.

A las múltiples procedencias que llevamos registradas, habría que sumar los obsequios que hacían los monjes cuando profesaban, regalando los libros que habían poseído en su vida en el siglo en signo de fidelidad, obediencia y pobreza. También hubieron de ser importantes las donaciones particulares, sobre todo las que llegaban en cumplimiento de mandas de testamento. El 31 de enero de 1263 se firmó una composición entre los monjes de Piedra y el clero de Molina en virtud de la cual, las personas que se mandasen enterrar en Piedra y dejaran bienes a favor de la abadía tributarían la décima de dichos bienes a la parroquia a la que hubieran estado adscritos en vida y si alguno

26 AHN: Clero, Piedra, carp. 3672, doc. 17, carp. 3673, doc. 4 y carp. 3674, doc. 3. Lumen Domus Petrae, Cod. 55, p. 853. Concepción CONTEL BAREA, El Cister Zaragozano en el siglo XII: Las abadias predecesoras de Nuestra Señora de Rueda de Ebro, Zaragoza, 1966. Joaquín Melendo Pomareta, Carenas, una historia a la sombra del Cister, Zaragoza, 2005.

27 Vicente de la Fuente, Historia de la siempre angusta y fidelísima ciudad de Calatayud. Calatayud, 1880, II, p. 57. Guido M. GIBERT, «Los estudios en la congregación cisterciense de los reinos de la corona de Aragón y Navarra», Los monjes y los Estudios. IV Semana de estudios Monásticos Poblet, Poblet, 1963, p. 395.

28 Antonio Serrano Montalvo, La población de Aragón segín el Fogaje de 1495, Zaragoza, 1995, p. 365-366. MELENDo PomaretA, Carenas, una historia a la sombra del Cister, p. 318. 
dexase al Monasterio algunos cálices o plata para hacerlos, o lienzo para la Iglesia o sacristía, o libros u otra cosa de bienes muebles y alajas para ornato de la Iglesia, de aquello no tubiesen parte alguna los clérigos de su parroquia. ${ }^{29}$ El 25 de abril de 1494, ante el notario bilbilitano Gil Sánchez Magallón, Nicolás Bernat, que era notario, vivía en Calatayud, había escriturado muchos documentos para Piedra y había asesorado a la abadía en ocasión de varios pleitos: dejó al convento la tercera parte de sus bienes [...] y dejó también para la librería [...] los libros del derecho canónico, y los de las decretales y los libros del Abad Panermitano, ${ }^{30}$ que es Nicolo de Tudeschi, uno de los grandes juristas del derecho canónico, autor de Lectura in decretales in sextum y In Clementina, Consilia, quaestiones, repetitioes, disputationes, disceptationes et allegationes y Flores utriusque juris, libros que le valieron el título de lucerna juris lámpara de la ley ${ }^{31}$. Hay una edición impresa en Venecia en 1477 que debe ser el libro que ingresó en Piedra.

Poca es la información existente para estudiar los iluminadores activos en Piedra. La más importante reliquia que se veneraba en la abadía era el Sacro Dubio de Cimballa, una Sagrada Forma que se transubstanció en 1380 para solventar las dudas de un sacerdote llamado mosén Tomás. La reliquia se conservó en Cimballa hasta que se hizo con ella Martín, Duque de Montblanc, hermano del rey Juan I, que llegó al trono como Martín I el Humano. En 1390 el duque Martín donó la reliquia a Piedra. Con motivo de tan significativo regalo, el abad Martín Ponce Pérez mandó hacer un retablo relicario, colocado en el altar mayor, fechado en 1390, hoy en la Real Academia de la Historia, cuyas tablas, atribuidas razonablemente a los hermanos Juan y Guillén de Levi, serían difíciles de entender sin el sistema de composición usado por los miniaturistas cuyo estilo estuvo a caballo entre el Trecento y el Estilo Internacional ${ }^{32}$. Unos años después de la donación, según documento dado en Zaragoza el 21 de noviembre de 1398, los habitantes de Cimballa recibieron en compensación por la reliquia una serie de exenciones, contenidas en un pergamino que, aunque no ha llegado a nuestros días, consta que se conservó en el archivo de Piedra, firmado por el notario real Juan Sancho, habitante de Nuévalos, descrito del siguiente modo:

Pende de la dicha copia con cordones de seda colorada un sello de plata sobredorada, que en una parte tiene las armas de Aragón, que son las barras solas Coronadas y alrededor una letra que dice: Martinus Rex Aragonum etcete. $=$ Y a la otra parte ay dos efigies del Rey y la Reyna, muy bien grabadas y, alrededor, una letra que dice: Adduxit eam in Monasterio

\footnotetext{
29 AHN: Lumen Domus Petrae, Cod. 55, p. 270.

30 AHN: Lumen Domus Petrae, Cod. 55, p. 736.

31 Wolfgang KNUT, Kirche und Konzil bei Nicolaus de Tudeschis, Colonia, 1964.

32 Herbert GonZÁlez ZyMla, El altar relicario del Monasterio de Piedra, Madrid, Zaragoza, 2013.
}

Titivillus, ISSN 2387-0915, ISSN-e 2603-9966, 1 (2015), pp. 13-26 
hoc. En la parte superior del pergamino ay pintado un ángel con los brazos abiertos, que tiene pendiente de las manos un corporal donde está pintada la forma del Santo Misterio. Y, a la parte inferior del pergamino están pintadas de buena mano y pincel con colorido diferentes: a saber es en el dicho lado derecho las dichas armas de Aragón con su letrero. Y al lado izquierdo los dichos Rey y Reina. ${ }^{33}$

Creo razonable pensar que el documento se redactó cuando Martín I visitó Piedra en 1398. El notario y el escribano eran habitantes de Nuévalos, y también lo debió ser el miniaturista que ornó el pergamino. Aunque excede el marco cronológico que habíamos marcado para el presente trabajo, hay que citar, por su excepcionalidad, en el Archivo Histórico Nacional, un trasunto, datado en Zaragoza el 24 de enero de 1550, hecho a instancias del arzobispo Hernando de Aragón, que contiene las Constituciones Provinciales de Zaragoza y de las diócesis sufragáneas dadas en 1396, en tiempos del arzobispo Pedro y del Papa Luna. El documento incluye, en uno de sus folios, una letra capital I a la que se asocia un premio lácteo de San Bernardo con el emblema heráldico del Monasterio: la trísquela. ${ }^{34}$

Por tanto, de los 9 libros identificados como procedentes de la Biblioteca del Monasterio de Piedra, 1 corresponde a finales del siglo XII, 3 corresponden al siglo XIV, 4 al siglo XV y 1 a los primeros años del XVI. En relación con el contenido hay 2 códices administrativos: el Libro de Bolsería y el Libro de Apeos; 4 códices litúrgicos: el Misal de Poblet, la Regla de San Benito, un Ritual Antiguo y el Salterio de Carenas; 2 códices de Visitas pastorales del abad Pedro Serrano y del abad García del Portillo y 1 libro de derecho canónico: el Panormitano. De los 9 libros, 2 se conservan en el Museo de Teruel, 1 en el Archivo Histórico Nacional y 1 en colección particular, estando los demás en paradero desconocido o perdidos. Se ha precisado la identidad de varios chantres, monjes notarios y cillereros-bolseros, que debieron ser los religiosos más activos en el scriptorium de Piedra. Así mismo, se ha identificado a un maestro escritor de libros de iglesia, Pascual Julián, y un iluminador, Pascual Pérez, habitantes de Carenas, y el legado de la biblioteca del notario Nicolás Bernat. Se atisba, tal como nos hizo observar la Doctora Carbajal González que Piedra pasó de ser un activo centro productor de manuscritos durante los siglos XIII y XIV a adquirir libros manuscritos e impresos en el incipiente mercado librario bilbilitano e la segunda mitad del siglo XV.

33 AHN: Lumen Domus Petrae, p. 231 y 232.

34 AHN: Clero, carp. 3715, doc. 4. Lumen Domus Petrae, Cod. 55, p. 113.

Titivillus, ISSN 2387-0915, ISSN-e 2603-9966, 1 (2015), pp. 13-26 


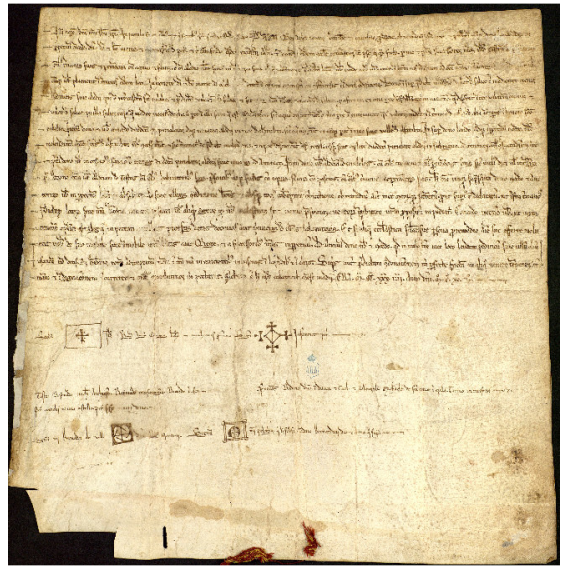

Lam. 1: Carta de donación dada por Alfonso II en 1195 a favor del abad Gaufredo de Rocaberti concediendo el Castillo de Piedra para fundar allí una abadía. A. H. N: Clero, carp. 3663, doc. 10.

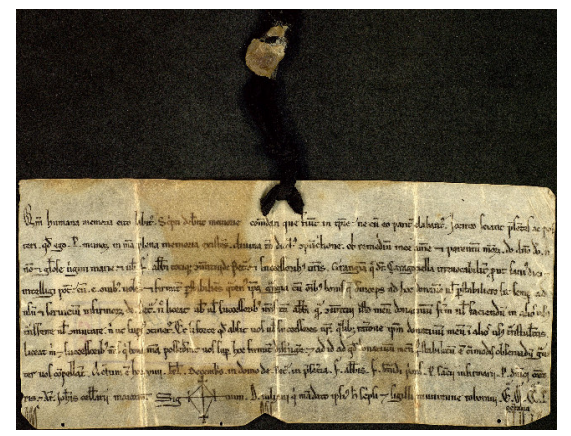

Lám. 2: Pedro Muñoz, el 23 de noviembre de 1220, dona sus propiedades en Zaragocilla al Monasterio de Piedra citando al Padre Domingo como monje Chantre. A. H. N: Clero, Piedra, carp. 3665, doc. 5.

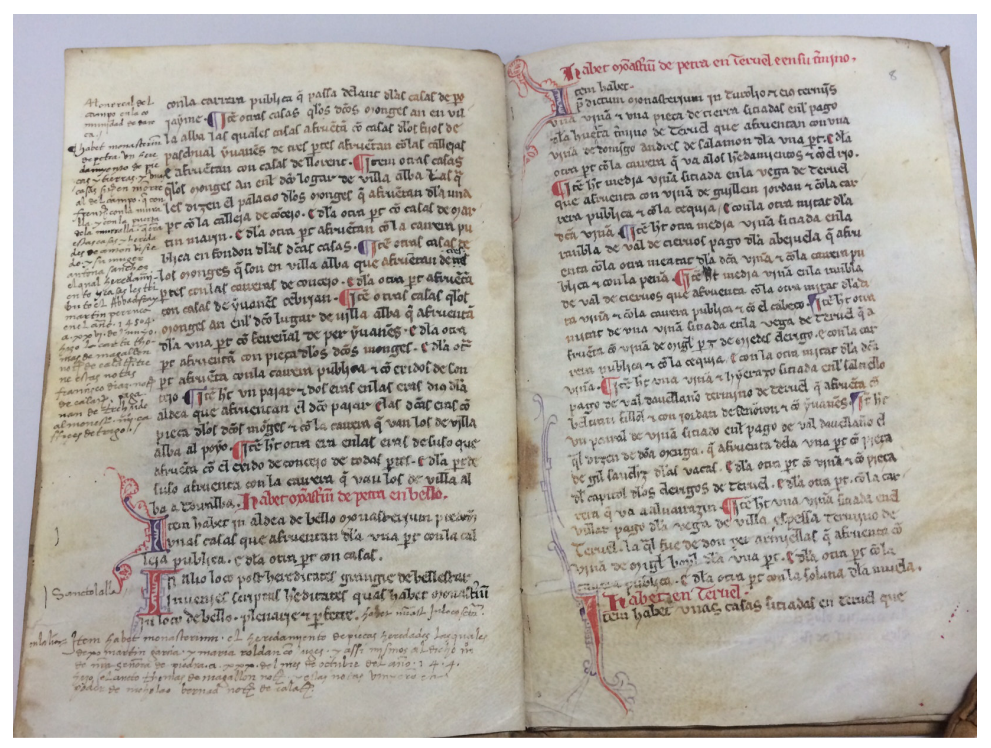

Lám. 3: Libro Cabreo Antiguo del Monasterio de Piedra, citado también como Libro de Bolsería, 13071348. Biblioteca del Museo de Teruel. 


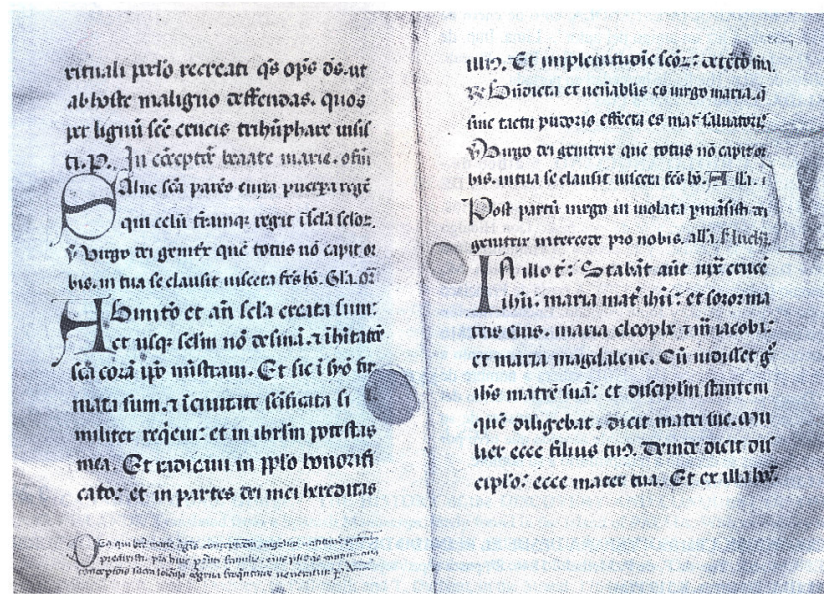

Lám. 4: Manuscrito que contiene la Regla de San Benito de Nursia, letra libraría aragonesa de mediados siglo XV, procedente del Monasterio de Piedra, subastado en 2002, hoy colección particular.

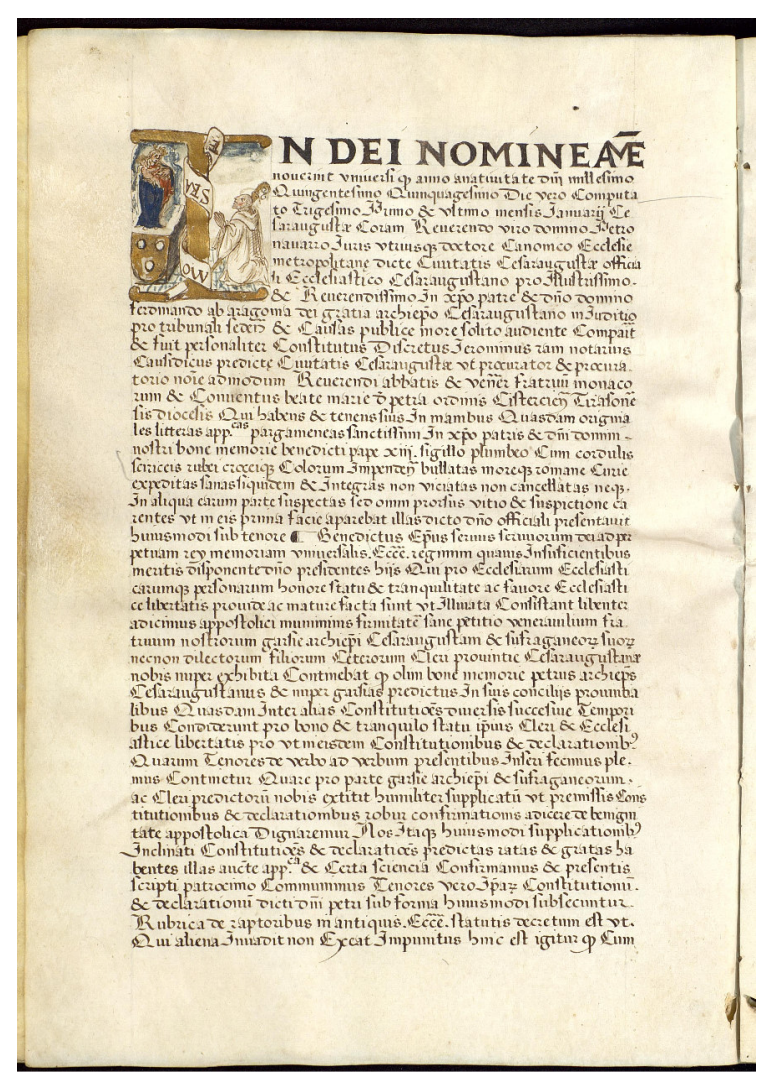

Lám. 5: Cuadernillo datado en Zaragoza el 24 de enero de 1550 , contiene trasunto de un original de Benedicto XIII dado en 1396, con las constituciones provinciales de Zaragoza de 1395. La letra inicial con el premio lácteo de San Bernardo en miniatura. A. H. N: Clero, carp. 3715 , doc. 4. 